\title{
Клініко-морфологічні особливості зубчастих колоректальних неопластичних утворень
}

\author{
О. Г. Курик ${ }^{1,2}$, М. Ю. Коломоєць ${ }^{1}$, В. О. Яковенко ${ }^{1,2,3}$, О. С. Губар ${ }^{1}$, \\ Р. П. Ткаченко ${ }^{1}$, В. В. Баздирев ${ }^{4}$ \\ ${ }^{1}$ Науково-практичний центр профілактичної та клінічної медицини, м. Київ, \\ ${ }^{2}$ Національний медичний університет імені О. О. Богомольця, м. Київ, \\ ${ }^{3}$ Медичний центр «Універсальна клініка «Оберіг», м. Київ, \\ ${ }^{4}$ Медична клініка «Інновація», м. Київ
}

\section{Clinico-morphological peculiarities of the toothed colorectal neoplastic tumors}

\author{
O. G. Kuryk ${ }^{1,2}$, M. Yu. Kolomoiets ${ }^{1}$, V. O. Yakovenko ${ }^{1,2,3}$, O. S. Gubar ${ }^{1}$, \\ R. P. Tkachenko', V. V. Bazdyrev ${ }^{\mathbf{1}}$ \\ ${ }^{1}$ Scientific-Practical Centre of Prophylactic and Clinical Medicine, Kyiv, \\ ${ }^{2}$ Bogomolets National Medical University, Kyiv, \\ ${ }^{3}$ Medical Centre "Universal Clinic "Oberig", Kyiv, \\ ${ }^{4}$ Medical Clinic "Innovation", Kyiv
}

\begin{abstract}
Реферат
Мета. Проаналізувати спостереження зубчастих неопластичних утворень (ЗНу), визначивши частоту їх виявлення особливості морфологічної будови.

Матеріали і методи. Проаналізовані результати морфологічного дослідження матеріалу, взятого під час діагностичної колоноскопії (ДКС) з біопсією, проведеної 376 пацієнтам.

Результати. У 289 (77,0\%) паціентів із 376 виявлено 1058 колоректальних поверхневих неопластичних утворень (КПнУ) Індекс виявлення КПНУ (кількість виявлених КПНУ по відношенню до загальної кількості обстежених пацієнтів) становив 2,81. Із 376 пацієнтів ЗНУ діагностовано у 157 (42\%) (95\% довірчого інтервалу (ДІ) 32,6-53,5), папілярно-тубулярні неопластичні утворення (ПТНУ) - у 248 (66\%) (95\% ДІ 58,2-70,8), причому у 116 (31\%) паціентів спостерігали одночасно ПТНУ і ЗНУ (95\% ДІ 28,6-42,7). Серед 1058 КПНУ діагностовано 672 (63,5\%) ПТНУ і 386 (36,5\%) - 3НУ, тобто ЗНУ виявляли достовірно рідше, ніж ПТНУ ( $<$ 0,01; відношення шансів 2,69). Серед 386 ЗНУ діагностовано 95 (24,6\%) гіперпластичних поліпів (ГП), 144 (37,2\%) ЗНУ на широкій основі (SSA), 74 (19,4\%) традиційних (TSA) і 73 (18,8\%) некласифікованих. Висновки. ЗНУ є частою колоректальною патологією. ДКС з видаленням ЗНУ - ефективний метод профілактики колоректального раку.

Ключові слова: товста кишка; зубчасті, папілярно-тубулярні неопластичні утворення; індекс виявлення

Abstract

Objective. To analyze the observations of the toothed neoplastic tumors (TNT), using determination of their occurrence rate and peculiarities of morphological structure.

Materials and methods. Results of morphological investigation were analyzed, concerning material, obtained during diagnostic colonoscopy (DCS) with biopsy, conducted in 376 patients.

Results. In 289 (77.0\%) patients of 376 there were revealed 1058 colorectal superficial neoplastic tumors (CSNT). Index of detection of CSNT (quantity of diagnosed CSNT in relation to general quantity of the patients examined) have constituted 2.81 Of 376 patients TNT was diagnosed in 157 (42\%) (95\% confidence interval (CI) 32.6-53.5), papillary-tubular neoplastic tumors (PTNT) - in 248 (66\%) (95\% CI 58.2-70.8), while in 116 (31\%) patients were observed simultaneously PTNT and TNT (95\% CI 28.6-42.7). Among 1058 CSNT were diagnosed 672 (63.5\%) PTNT and 386 (36.5\%) TNT, thus TNT was revealed trustworthily less frequently, than PTNT ( $<<0.01$; the odds ratio 2.69). Among 386 TNT were diagnosed 95 (24.6\%) hyperplastic polyps, 144 (37.2\%) TNT on a wide base, 74 (19.4\%) conventional and 73 (18.8\%) nonclassified.

Conclusion. TNT constitutes a prevalent colorectal pathology. DCS with excision of TNT is effective method of prophylaxis of colorectal cancer.

Keywords: large bowel; toothed, papillary-tubular neoplastic tumors; index of detection.
\end{abstract}

В останні десятиріччя у більшості країн світу невпинно зростають показники захворюваності на колоректальний рак [1]. Надзвичайно актуальною є проблема діагностики раннього колоректального раку і передракових захворювань, насамперед поліповидних і неполіповидних КПНУ. Визнано необхідність ДКС з видаленням цих утворень [2], що є діагностичною і лікувальною маніпуляцією. Методи ендоскопічного дослідження із застосуванням методик відеоколоноскопії, хромоскопії, ендоско- пії зі збільшенням, дослідження у вузькому спектрі дають можливість оцінити стан слизової оболонки кишечника і здійснити прицільну біопсію з патологічно змінених ділянок [3]. Мікроскопічне дослідження дає можливість встановити гістологічну будову КПНУ, що є основою для визначення подальшої тактики лікування пацієнта; також дедалі більшого значення набуває вивчення пато- і морфогенезу КПНУ із визначенням потенціалу їх малігнізації. ЗНУ як різновид КПНУ слизової оболонки товстої киш- 


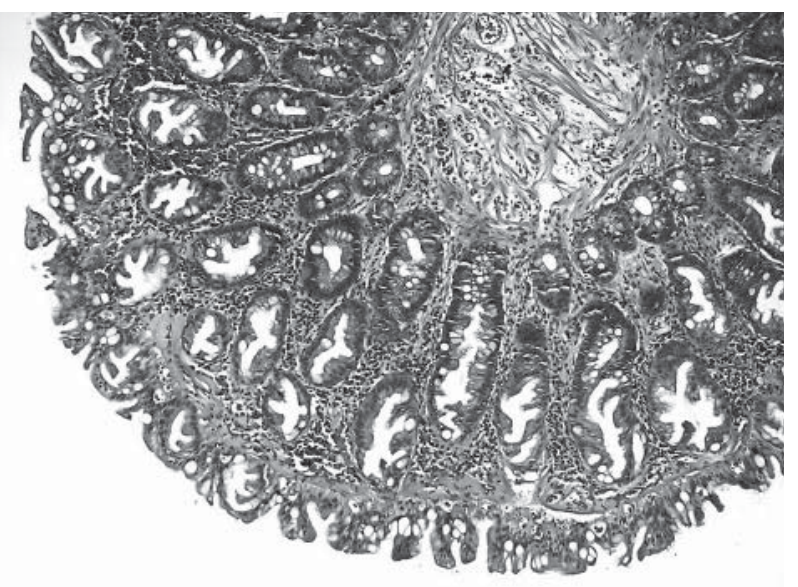

Puc. 1 .

Гіперпластичний поліп.

Забарвлення гематоксиліном та еозином. $36 . \times 200$.

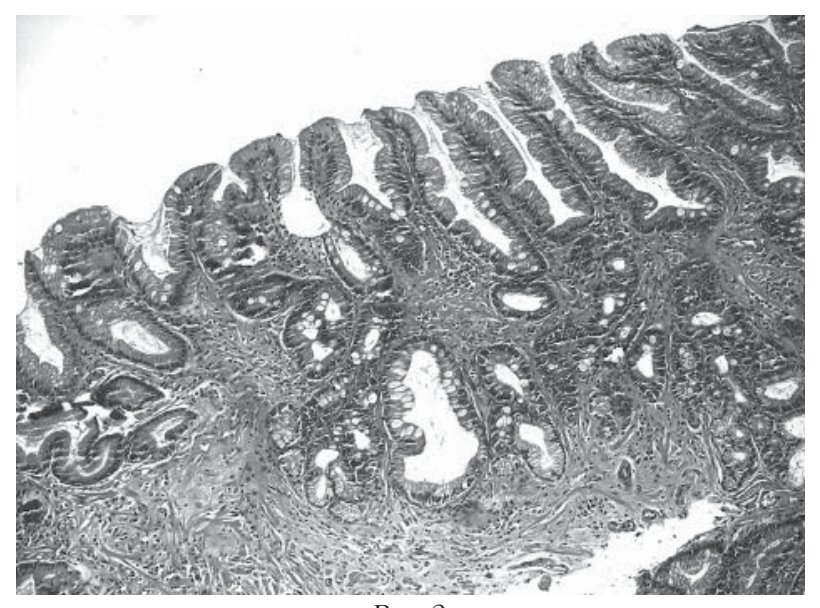

Puc.2.

Зубчаста аденома на широкій основі (SSA).

Забарвлення гематоксиліном та еозином. 3б. ×200. ки почали діагностувати лише наприкінці минулого століття. У 1990 р. T. Longacre і C. Fenoglio-Preiser вперше застосували термін «зубчаста аденома» (3А) [4], а у 2003 р. E. Torlacovic і співавтори розділили ЗА на дві групи - традиційні (TSA - traditional sessie adenoma) і 3А на широкій основі (SSA - sessile serrated adenoma) [5]. У класифікації ВООЗ 2010 р. серед передпухлинних утворень товстої кишки виділено ЗНУ, що включають ГП, SSA і TSA [6].

Дослідники вважають, що всі ЗНУ мають канцерогенний потенціал [7]. Пусковим механізмом зубчастого канцерогенезу є мутація гена BRAF, внаслідок чого порушуються процеси проліферації, диференціювання і апоптозу епітеліоцитів і виникає зубчасте утворення товстої кишки. В подальшому відбувається епігенетична інактивація ряду генів, зокрема гена hMLHI, що відповідає за корекцію похибок реплікації дезоксирибонуклеїнової кислоти. Часте виникнення множинних додаткових мутацій зумовлює відносно швидкий розвиток цитологічної дисплазії та злоякісної трансформації пухлини [8].

Проблемі діагностики ЗНУ присвячена велика кількість англомовних публікацій і поодинокі російськомовні повідомлення. В Україні опубліковано дослідження, де широко висвітлені питання етіології, патогенезу, ендоскопіч-

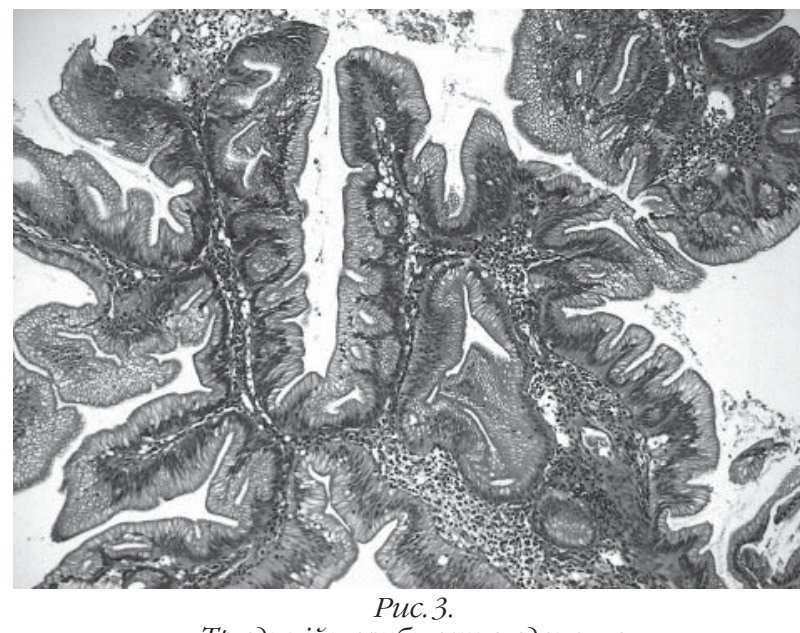

Традиійна зубчаста аденома.

Забарвлення гематоксиліном та еозином. $36 . \times 200$.

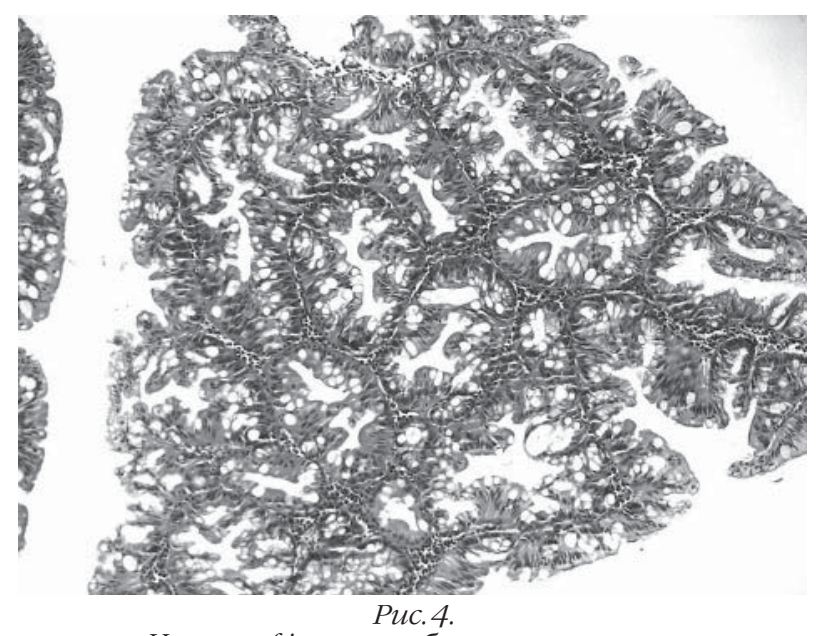

Некласифіковане зубчасте утворення.

Забарвлення гематоксиліном та еозином. 3б. ×200.

ної і морфологічної діагностики ЗНУ, однак воно має оглядовий характер [9]; клініко-морфологічні особливості ЗНУ на власному матеріалі описані лише у двох роботах $[10,11]$. Поширеність ЗНУ, ї морфологічні особливості в популяції українських пацієнтів потребують подальшого вивчення з урахуванням зростання захворюваності на рак товстої кишки.

Мета дослідження: проаналізувати спостереження ЗНУ, визначивши їх частоту, зокрема, у порівнянні з частотою ПТНУ, а також особливості морфологічної будови.

\section{Матеріали і методи дослідження}

Проаналізовано результати морфологічного дослідження матеріалу, взятого під час проведення ДКС із біопсією (відеоендоскопи Olympus CF-150, Olympus GIF160Z, Olympus Optical CoLTD), у 2014 - 2016 рр. на базі НПЦ ПКМ ДУС і Медичного центру «Універсальна клініка «Оберіг».

Обстежено 376 пацієнтів у віці 18-86 років, середній вік - (52 \pm 14$)$ років. Чоловіків було 194 (51,6\%) у віці 18 - 80 років, середній вік - (51 \pm 13$)$ років, жінок - 182 (48,4\%) у віці 22 - 86 років, середній вік - (50 \pm 12$)$ років. Фіксували всі КПНУ, виявлені під час ДКС. 


\section{Результати}

У 289 (77,0\%) пацієнтів із 376 виявлено 1058 КПНУ. Індекс виявлення КПНУ становив 2,81: у чоловіків - 3,25, у жінок - 2,36, різниця статистично достовірна $(\mathrm{p}<0,05)$. КПНУ достовірно частіше (74\%) локалізувалися у лівій частині товстої кишки ( $<0,01)$. Із 376 хворих ЗНУ діагностовано у 157 (42\%) (95\%ДІ 32,6-53,5), ПТНУ - у 248 (66\%) (95\%ДІ 58,2-70,8), причому у 116 (31\%) пацієнтів спостерігали одночасно ПТНУ і ЗНУ (95\%ДІ 28,6-42,7). Серед усіх 1058 КПНУ діагностовано 672 (63,5\%) ПТНУ і 386 (36,5\%) - ЗНУ, тобто ЗНУ виявляли достовірно рідше, ніж ПТНУ ( $<<0,01 ;$ відношення шансів 2,69).

\section{Обговорення}

Отримані нами дані щодо частоти виявлення КПНУ під час ДКС підтверджують, що ця патологія є поширеною. Різниця між кількістю чоловіків і кількістю жінок із КПНУ виявилася статистично недостовірною (p > 0,1). Щодо локалізації КПНУ, то більшість їх було знайдено у лівій частині товстої кишки (p <0,01), що збігається з даними інших авторів [7, 9].

Останнім часом щодо ЗНУ дослідники дотримуються думки, що їм у значній мірі властиво прогресування в аденокарциному, однак потенціал малігнізації залишається вищим у незубчастих КПНУ $[12,13]$. Критерієм малігнізації вважається проростання окремих епітеліальних комплексів у власну м'язову мембрану слизової оболонки або крізь неї у власну підслизову основу.

В діагностиці ЗНУ ми керувалися класифікацією ВООЗ 2010 року [6], рекомендаціями експертної групи D. Rex i співавторів [14], а також підходами, розробленими О. А Харловою і співавторами [15]. Критеріями визначення ГП вважали наявність зубчастості у верхній половині крипт, видовжених недеформованих крипт, базальні відділи яких мали тубулярну будову без ознак розгалуження, дилатації і горизонтального росту, відсутність псевдостратифікації ядер, еозинофільних змін епітелію, ознак клітинної атипії (puc. 1); SSA - поширення зубчастості на всю глибину крипт, наявність хоча б однієї крипти з вираженими архітектурними порушеннями - дилатація базальних відділів, горизонтальний ріст базальних відділів вздовж м'язової пластинки, відсутність псевдостратифікації ядер, еозинофільних змін епітелію, цитологічної атипії (рис. 2); 3НУ на широкій основі з дисплазією - наявність вогнищ цитологічної атипіі; традиційної ЗА - ектопічні крипти, які короткі, відходять під прямим кутом і не досягають м'язової пластинки, а також еозинофільні зміни епітелію, що являють собою високі стовпчасті клітини з еозинофільною цитоплазмою і центрально розміщеним видовженим ядром (рис. 3). Ознаки клітинної атипії можуть бути різного ступеня вираженості і мати вогнищевий або дифузний характер.

Частина авторів виділяе так звані некласифіковані зубчасті утворення, які за морфологічною будовою не можуть бути віднесені ні до одніеї з трьох груп класифікації (рис. 4), що пов'язано або з особливостями морфологічної будови, або з недостатньою кількістю матеріалу, взятого під час біопсії [15].Серед досліджуваних нами 386 зубчастих КПНУ діагностовано 95 (24,6\%) ГП, 144 (37,2\%) SSA, 74 (19,4\%) TSA і 73 (18,8\%) некласифікованих зубчастих утворень.

\section{Висновки}

1. ЗНУ є частою патологією слизової оболонки товстої кишки, яку виявляють у 42\% пацієнтів під час ДКС, ці утворення становлять 36,5\% всіх виявлених КПНУ.

2. Досі немає чітких критеріїв ендоскопічної і морфологічної діагностики ЗНУ, не визначені ознаки щодо прогнозування можливостей і швидкості їх малігнізації. Розробка алгоритму диференціальної діагностики різних типів ЗНУ $є$ важливим етапом у подальшому вивченні їх біологічних і молекулярно-генетичних особливостей для розуміння патогенезу колоректального раку.

3. 3 урахуванням того, що ЗНУ мають достатньо високий ризик злоякісного перетворення, своєчасне виявлення і ендоскопічне їх видалення є необхідною профілактикою розвитку зубчастого колоректального раку.

\section{Reference}

1. Rak v Ukraini, 2015-2016: zabolevayemost, smertnost, pokaznyky diyalnosti oncologichnoi sluzhby. Bulleten Natsionalnoho cancer-reyestra Ukrainy. 2017;18:26-30.

2. Yakovenko VO, Kuryk OG. Endoscopychna resekciya slyzovoi obolonky kyshechnika z pryvodu kolorektalnoi neoplazii. Klinichna chirurgia. 2013;12:25-7.

3. Zakharash MP, Yakovenko VO, Kuryk OG. NBI i endoscopiya z vysokym zbilshennyam: suchasni mozhlyvosty endoskopichnoi dyagnostiki. Ukrainskiy zhurnal maloinvazyvnoi i endoscopichnoi chirurgii. 2009;13(4):12-5.

4. Longacre T, Fenoglio-Preiser C. Mixed hyperplastic adenomatous polyps / serrated adenomas. A distinct form of colorectal neoplasia. Am J Surg Pathol. 1990;14:524-37.

5. Torlakovic E, Skovlund E, Snover D, Nesland IM. Morphologic reappraisal ofserrated colorectal polyps . J Surg Pathol. 2003;27:65-81.

6. Snover DC, Ahnen DJ, Burt RW, Odze RD. Serrated polyps of the colon and rectum and serrated («hyperplastic») polyposis. In: Bozman FT, Carneiro F, Hruban RH, Theise N, eds. WHO classification of tumours. Pathology and genetics. Tumours of the digestive system . 4th ed. Lyon: IARC Press; 2010:160-5.

7. Ageikina NV, Duvanskiy VA, Knyazev MV. Alternativniy put razvitiya kolorektalnogo raka. Histogeneticheskye i molekulyarnye osobennosty zybchatych porazheniy. Ekperimentalnaya Klinicheskaya Gastroenterologiya. 2014:7(107):5-13.

8. O’Brien M, Zhao Q, Yang S. Colorectal Serrated Pathway Cancers and Precursors. Histopathology. 2015;66:49-65.

9. Nikishayev VI, Patiy AP, Tumak IN, Kolyada IA. Endoscopicheskaya diagnostica rannego kolorektalnogo raka. Ukrainskiy zhurnal maloinvasivnoi ta endoskopichnoi chirurgii. 2012:16(1):35-55.

10. Kostoglodov AV, Yakovenko VO, Bodnar LV, Bazdyryev VV. Morphologichna diagnostica zubchatyh neoplasiy tovstoi kyshky. Ukrainskiy zhurnal maloinvasivnoi ta endoskopichnoi chirurgii. 2014;1(79):70-2.

11. Kuryk OG, Yakovenko VO, Bazdyryev VV. Morphologicheskaya diagnostica zubchatyh neoplasiy toltoy kyshky. ScienceRise. 2015;7/4(12):69-73.

12. Yamane L, Scapulatempo-Neto C, Reis RM, Guimarães DP. Serrated pathway in colorectal carcinogenesis. World J Gastroenterol. 2014 Mar 14;20(10):2634-40.

13. Singh R, Zorron Cheng Tao Pu L, Koay D, Burt A. Sessile serrated adenoma/polyps: Where are we at in 2016? World J Gastroenterol. 2016;22(34):7754-9.

14. Rex DK, Ahnen DJ, Baron JA, Batts KP, Burke CA, Burt RW et al. Serrated lesions of the colorectum: review and recommendations from an expert panel. The American Journal of Gastroenterology. 2012;107 (9),1315-29.

15. Harlova OA, Danylova NV, Malkov PG, Ageikina NV, Knyazev MV. Kliniko-morphologicheskiye osobennosty zubchatyh obrazovaniy tolstoy kyshky. Archiv pathologii. 2015;4:24-32. 